\title{
Factors Discriminating Inventory Management Performance: An Exploratory Study of Indian Machine Tool SMEs
}

\author{
Rajeev Narayanapillai \\ Department of Mechanical Engineering, NSS College of Engineering, (India) \\ rajeevmalivil@gmail.com
}

Received: August 2013

Accepted: April 2014

\section{Abstract:}

Purpose: There are many kinds of methods to evaluate the inventory management and economic performance of small and medium enterprises, but they still have some distinct shortcomings. In order to achieve a better evaluation result, we put forward a new model based on the evidences from developing country like India.

Design/methodology/approach: This survey study, mainly based on the evidences from machine tool SMEs in India uses statistical methods to avoid the drawbacks of qualitative techniques.

Findings: Through empirical data, it is established that 'technology' is not the only concern, but other factors related to human resource, economic, organizational and behavioral aspects of SMEs are also vital in improving their IM performance.

Originality/value: This study combines the role of factors such as managerial, technological, economical and contingency together for the first time in the context of SMEs.

Keywords: inventory management, inventory management performance, machine tool, SMEs 


\section{Introduction}

Small and Medium Enterprises (SMEs) occupy a place of strategic importance in developing as well as developed countries owing to its considerable contribution to national income, employment, exports, and entrepreneurship development (Saxena, 2012). Therefore, in the development process of any country, the performance of SMEs based on competition, productivity and efficiency will play a significant role (Nanjundan, 1994). The competition due to economic reforms and globalization has put more pressure on SMEs (Huin, 2004). It is observed from literature that making use of formal Inventory Management (IM) practices is one of the ways to acquire competitiveness among others, by effectively managing and minimizing inventory investment (Sprague \& Wacker, 1996).

Zeng and Hayya (1999) described the major functions of inventory as: (1) to support and provide necessary inputs for manufacturing; and (2) to protect companies against uncertainties that arise from such cases as discrepancy between demand and production, machine deterioration, and human errors, among others. They further argue that regardless of the type of a firm, the management effectiveness of inventory decisions centers on three areas: cost, service level, and turnover ratio. This implies that inventory cost (Bhagwath \& Sharma,2007) and turnover are very important in deciding the IM strategy of firms and Inventory Turnover Ratio (ITR) is a measure of how effectively inventories are being managed (Zeng \& Hayya, 1999). IM has significance for any enterprise in an inventory intensive manufacturing industry, because effective IM will enable an enterprise to minimize inventory cost on the one hand and avoid the consequence of shortage of materials on the other. This assumes significance in the particular context of SMEs, because excess inventory and shortage of materials are often the two main problems found in SMEs regarding IM (Eloranta \& Raisanen, 1988).

In India the inventory related aspects of SMEs have not yet attracted the attention of researchers and policy makers to any discernible level. The SMEs, specially manufacturing enterprises, which contribute significantly to Indian economy in several ways, use significant amount of materials but are found striving for inventory utilization, inventory efficiency and other aspects like inventory measurement. As materials make a substantial contribution to output in many SMEs, there is a need for firms to adopt formal IM practices as a 'cost cutting' or 'profit maximizing' strategy. There is hardly any study found in the literature on IM even in the context of inventory intensive manufacturing Indian SMEs of any particular sector from any region of the country. Considering the lack of studies in the Indian context the present study aims at probing the following issues. What are the IM practices pursued by SMES? What are the factors that influence and discriminate IM performance of SMES? The main contribution of this paper is that 
apparently no study has attempted to answer these questions in the context of Indian SMEs.

The paper is organized in five sections. Literature review is presented in section 2 and section 3 presents the objectives, scope and methodology. Section 4 comprises analysis of IM Practices and IM Performance in Indian SMEs section 5 discusses identification and measurement of factors discriminating IM performance followed by summary of the study explained in Section 6.

\section{Inventory Management in SMEs: A Review of literature}

Many researchers have analyzed different IM practices and performance and these studies have amassed an enormous knowledge related to IM and operational performance of enterprises. Maria and Jones (2003) argue that implementation of proper IM practice involves providing high quality products at relatively less cost. They further pointed out that it is essential to establish a daily ordering and frequent calculation of inventory turns. On the other hand Ballou (2000) argues that inventory cost should be considered while taking inventory decisions. He found that inventory carrying costs typically range from $20 \%$ to $40 \%$ of inventory value. Palmer and Dean (2000) are of the opinion that selection of right IM practice is a must for a company's IM performance.

The linkages between IM and competitive advantages have been discussed by many authors in the context of large enterprises (Natarajan, 1991). Reducing throughput time by faster value addition to the materials clearly would lead to a competitive edge. This would lead to advantage on the inventory cost front also. Inventory costs are reduced as materials spend less time in the system. He brings out another point: inventory costs are determined not only by the level but also by duration of time materials spend in the system. The importance of lead-time as a measure of inventory effectiveness has been mentioned by Rabinovitch, Martin and Philip (2003). Ng, Partington and Sculli (1993) are of the opinion that long lead times and large usage fluctuation call for higher re-order stock levels and vice-versa. Further they pointed out that the nature of inventory item along with the importance attached to each item in the production process has an important role in determining the amount of inventory to be kept in enterprises.

Chandra and Grabis (2005) argue that a reduction in the inventory replenishment lead-time allows reducing safety stock and improving customer service. Wallin, Rugtusanatham and Rabinovitch (2006) also view lead-time as an important inventory element. However, both throughput time and lead-time depend on the product and production practices followed by the firm and therefore, determined by a set of interrelated factors (Natarajan, 1991). On the other hand, Gill, Biger and Mathur (2010) argue that excess inventory is an operational liability, 
because it uses valuable storage space, increases inventory costs. Raw material ordering frequency is identified as an important factor contributing to inventory cost. Frequent ordering in small quantity is considered as an important strategy. This is very relevant in the context of SMEs. This is because SMEs generally don't get the benefits of quantity discount. Their purchase requirement quantity of material is normally less to enable them to get these benefits. Hence for SMEs frequent purchasing is appreciated.

A project to improve IM in a UK based SME found the importance of categorizing stock and setting ordering policies. A scheme developed for the above purpose found useful in optimizing inventory costs (Flores, Wang \& Burgess, 2003). The management of SME studied viewed the need for a more formal procedure to calculate its inventory policy parameters (maximum and minimum inventory level). In their own words, the growing investment in inventory combined with an increasing number of backorders and lost sales lead to lower profitability. Therefore it was decided to follow a more scientific approach than the currently used rules of thumb to establish inventory policy parameters with the objective of optimizing their inventory cost.

Koumanakos (2008) in his study aimed at testing the hypothesis that efficient IM leads to an improvement in a firm's financial performance. The results revealed that the higher the level of inventories preserved, departing from a lean manufacturing, by an enterprise the lower is its rate of returns. Jonsson and Mattsson (2008) studied the use of material planning methods to control material flow inventories of purchased items. The study explored the perceived planning performance of material planning methods used to control material flow in different types in manufacturing and distribution companies. They also evaluated the difference in perceived planning performance depending on the way planning parameters are determined and the methods used. Altogether five material planning methods were studied based on a survey data. However, Koh, Deirbag, Bayraktar, Tatoglou and Zaim (2007) probed a more prominent issue regarding the underlying dimensions of Supply Chain Management (SCM) practices and to test a framework identifying the relationships among various SCM practices, operational performance and SCM related organizational performance. The survey study was conducted on SMEs in Turkey. The study brought out that both strategic collaboration and lean practices (SCLP) and outsourcing and multi suppliers (OMS) factors have direct positive and significant impact on operational performance of SMEs. However, the study found that both factors have no direct impact on SCM related organizational performance and only indirect and significant positive effect. Whereas, the observation by Teunter, Babai and Syntetos (2012) was that $A B C$ analysis is commonly used as an IM practice in SMEs worldwide.

To exercise inventory planning and control, the understanding of the factors influencing IM is necessary. This will enable SMEs to select an appropriate IM practice in their enterprise. Though the role of IM practices of a firm, their inventory cost on order quantity and hence on inventory performance is well explained in theory, an empirical evaluation of the same is not done so far in the context of SMEs, particularly in developing countries. In this context, this 
study is an attempt to identify the factors influencing inventory cost with respect to the machine tool SMEs in Bangalore.

\section{Objectives, Scope and Methodology}

The study found that it is the combination of technical factors, managerial factors, organizational factors and economic factors which would determine the level of IM performance of SMEs. It is in this backdrop that we set the objectives of the present study. The specific objectives of the study are as follows:

- To study IM practices pursued and related issues in SMEs.

- To probe what factors discriminate IM performance of Indian SMEs

\subsection{Scope and Methodology of the study}

The study is confined to machine tools industry in the city of Bangalore in India. Machine tools industry is rather the most important manufacturing industry concentrated in and around Bangalore (PIA, 2003). It is also considered an inventory intensive industry having formal or informal relationship with various large enterprises including Multi Nationals (MNCs) located in the city. The quality and cost of engineering products depends on the quality of parent machine tools industry and their automation levels. The development of machine tool industry is therefore of paramount importance for a competitive and self-reliant industrial structure. Therefore, this sector is considered appropriate for our study.

As there is no systematic database of machine tool SMEs located in Bangalore, we decided to focus on a maximum number of 80 SMEs in this sector. From these SMEs we gathered primary data through a semi structured questionnaire having five sections on basic features, IM practices and performance, economic variables, production details, factors hindering/ facilitating IM etc. Respondents were asked to gauge the extent to which they agreed with the given statements regarding each question. Mostly items were formulated as short statements and respondents were asked to provide their views on a five point Likert scale. The data collection exercise was carried out by the author himself during September 2006 to February 2007. From a total of 80 SMEs covered, 11 enterprises were eliminated due to incomplete information, inadequacy of data etc. Finally data from 69 SMEs were considered for the final analysis. The population for the study is the set of all machine tools SMEs operating in the city of Bangalore, having original investment in plant and machinery not exceeding Rs. 100 millions. There are about 350 machine tool SMEs in the city of Bangalore as per the PIA directory and 69 out of $350(19.71 \%)$ are selected for this study and therefore the sample size 
is not small. This was further substantiated by determining the sample size using the formula for finite sample size (Sekaran, 2003). The methodologies adopted for the data analysis are descriptive analysis, multiple regression analysis using dummy variables and discriminant analysis.

\section{Analysis of IM Practices and IM Performance in Indian SMEs}

Since the machine tool SMEs are inventory-intensive in nature with a significant portion of their production cost involving material and inventory related cost, it is likely that the entrepreneurs recognize its due importance. Therefore, at the outset, we are keen to know how many of the 69 surveyed SME enterprises have considered IM a very important concept in their enterprise. IM is important because it can ensure that the materials necessary for production and finished products for distribution are available in the correct quantities and at the right time ( $\mathrm{Ng}$ et al., 1993). Given this IM is important for SMEs as much as for large firms.

In fact organizations, where management professionals are not experts in management science techniques, do not use any inventory models or methods. Instead they go on taking decisions based mostly on intuition and sometimes on elementary inventory control or methods (Mohanty, 1985). In SMEs, it is highly unlikely that the entrepreneurs would have the requisite background of management science techniques. Therefore, application of formal IM practices may not significantly present in SMEs. This could be because SMEs in general are constrained in terms of resources of various kinds such as finance, skilled labour etc. In the midst of constraints, though SMEs might realize the importance and need for pursuing an IM practice, they will not be in a position to pursue them. But at the same time, it may not be appropriate to assume that IM practices are totally absent in SMEs in general and in developing countries in particular.

It is with the above backdrop that understanding the present perception of SMEs about the importance of IM is appropriate. Out of 69 SMEs surveyed, all the SMEs explicitly stated that IM is very important for a firm's performance. This brings out that the level of awareness about the need and importance of IM practices is significantly high among the machine tool SMEs of Bangalore. Given this, it is appropriate to look at these SMEs to ascertain how many of them follow IM practices and what kinds of IM practices do they pursue. Table 1 presents data on how many SMEs follow IM practices and what kind of IM practices are pursued. 


\begin{tabular}{|c|c|c|}
\hline SI. No & IM practice followed & Number of firms \\
\hline 1 & Heuristics & 37 \\
\hline 2 & ABC & 18 \\
\hline 3 & Computerized Inventory Accounting & 4 \\
\hline 4 & Vendor Managed Inventory (VMI) & 10 \\
\hline \multicolumn{2}{r}{ Total } & 69 \\
\hline
\end{tabular}

Table 1. IM Practices followed in SMEs

Among various kinds of IM practices, the most significant one pursued by the maximum number of SMEs is that based on heuristics: 37 of the 69 enterprises followed IM practices based on thumb rules. Therefore, it is essential to probe this issue further. The breakdown of SMEs in terms of the heuristics pursued is presented in Table 2. It is observed that 15 out of 69 SMEs pursue IM practice based on routine heuristic. Another 12 SMEs pursue IM practices based on heuristics based on the situation such as high demand, quantity discount, anticipation of price hike etc. This is referred to as situation based heuristics in this study. About 4 SMEs follow order based heuristics. About 6 SMEs pursue ABC heuristically. The study brought out that even in inventory intensive manufacturing SMEs like machine tools IM practices are pursued on a heuristic basis. The poor IM performance as indicated by the ITR values further revealed that there is amble scope for SMEs to improve their IM performance by pursuing modern IM practices such as computerized inventory accounting and VMI.

\begin{tabular}{|c|c|c|}
\hline SI No & Heuristics pursued & Number of SMEs \\
\hline 1. & Routine Heuristics & 15 \\
\hline 2. & Situation based heuristics & 12 \\
\hline 3. & Order quantity based heuristics & 4 \\
\hline 4. & ABC based heuristics & 6 \\
\hline \multicolumn{2}{r|}{ Total } & 37 \\
\hline
\end{tabular}

Table 2. Heuristics pursued by SMEs

The second most significant IM practice followed by SMEs is ABC (18 firms). SMEs which pursued computerized IM techniques are only four and about 10 of them followed VMI. All these bring out that modern IM practices are largely absent among Indian SMEs, even in an inventory-intensive manufacturing industry. 


\section{Identification and Measurement of Factors discriminating IM performance}

Based on the literature review the theoretical framework of the present study has been developed. The possible factors that would influence IM performance can be broadly classified as technical factors, managerial factors, organizational factors and contingency factors. Under these four broad groups, 16 specific variables have been identified which are: (1) Safety stock planning of enterprise (SFSTPL), (2) Capacity utilization level of enterprise (CAPUTN), (3) Purchasing effectiveness (PUREFF), (4) Demand variability of the product (DEVARB), (5) Demand forecasting frequency (DEFRFQ), (6) Raw material ordering frequency (RMORFQ), (7) IM practices pursued (IMPRPD), (8) Product type (PRTYPE), (9) Lead time (LDTIME), (10) Management attitude (MGMTAT), (11) Employees training (EMPLTR), (12) Space limitation (SPALIM), (13) Interaction with suppliers (INTSUP), (14) Interaction with customers (INTCUS), (15) Supplier empowerment (SUPEMP) and (16) Inventory cost (INCOST) respectively.

All these variables which would possibly influence the IM performance in a SME are considered equally important and are measured on a five point Likert scale. The values of these variables which are subsequently used for the analysis are either directly obtained or logically derived from the empirical data obtained through field survey. Since we presume that each of these 16 variables is going to capture one dimension of IM performance, entire combination of these variables is treated as one set for our analysis. To consider the level of influence of these variables on IM performance: a score of 1 indicates least influence whereas a score of 5 indicates the highest influence of the variable on IM performance. Each of the sample SME has given a score for each of the 16 variables. To begin with we wanted to check that all the 16 variables have a statistically significant correlation with IM performance and we found that all the 16 variables have a statistically significant correlation with the IM performance.

\begin{tabular}{|l|l|l|}
\hline \multirow{2}{*}{ Technical factors } & (1) Raw material ordering frequency & ROF \\
\hline & (2) Demand forecasting frequency & DEFRFQ \\
\hline & (3) Purchasing effectiveness & PUREFF \\
\hline & (4) Lead time Inventory cost & LT \\
\hline Managerial Factors & (6) IM practices pursued & ICOST \\
\hline & (7) Safety stock planning of enterprise & IMPRPD \\
\hline & (8) Employees training & EMPLTR \\
\hline Contingency Factors & (9) Management attitude & MGMTAT \\
\hline (10) Capacity utilization level of enterprise & CAPUTN \\
\hline Organizational Factors & (11) Product type & PT \\
\hline & (12) Demand variability of the product & DV \\
\hline & (14) Interaction with suppliers & INTSUP \\
\hline (15) Supplier empowerment & INTCUS \\
\hline & (16) Space limitation & SUPEMP \\
\hline
\end{tabular}

Table 3. Possible factors that would influence IM performance 
We further conducted a factor analysis using principal component analysis to select the most important variables and found out that four of the 16 variables are not substantially loading on their intended factors as revealed by the rotated component matrix. These variables are Raw Material Ordering Frequency (ROF), Lead Time (LT), Space Limitation (SL) and Inventory Cost (ICOST) respectively. Two variables, namely, Demand Variability of the product (DV) and Product Type $(P T)$ independently loaded on their respective factor. Therefore, further analysis is done with the remaining 10 variables.

To ascertain which among the 10 variables identified and supposed to influence the IM performance of SMEs (as proposed in the theoretical framework) discriminate different SMEs which have different levels of IM performance, discriminant analysis is carried out for three groups of SMEs namely performing, moderately performing and non performing SMEs. The purpose of carrying out discriminant analysis is two fold:

- To find out which among the 10 variables discriminate between performing, moderately performing, and non performing groups.

- To establish the relative importance of variables and choosing the most important among them.

The SMEs are classified under three different groups based on their ITR values: Group 1: Those SMEs whose ITR value fall between $>0-2.5$, Group 2: Those SMEs whose ITR value fall between $>2.5$ - 5 and Group 3: Those SMEs whose ITR value is above 5. In discriminant analysis, a linear combination of the independent variables is formed and serves as the basis of assigning cases to groups.

The discriminant function for group is given as: $G=a+b_{1} X_{1}{ }^{*}+b_{2} X_{2}{ }^{*}+\cdots+b_{10} x_{10}{ }^{*}$, where $x_{1}, X_{2}, X_{3}, \cdots, X_{10}$ represent the 10 variables emerged

The maximum number of discriminant functions will be equal to the number of groups minus one or the number of variables in the discriminant function, whichever is smaller. Since in the present analysis there are three groups and 10 variables in the discriminant function, there will be two discriminant functions for the analysis. The result of the discriminant analysis is shown below. 


\subsection{Discriminant Functions}

The Eigen values for the discriminant functions are given in Table 4. Eigen values for the two discriminant functions are positive and when more than two groups are analysed, the sign of each Eigen value is helpful for measuring the spread of the group centroids in the corresponding dimension of the multivariate space. The Eigen value of function 1 is high indicating that it is a good discriminant function in separating the groups.

\begin{tabular}{|c|c|c|c|c|}
\hline Function & Eigenvalue & \% of Variance & Cumulative \% & Canonical Correlation \\
\hline 1 & 24.636 & 97.0 & 97.0 & .980 \\
\hline 2 & .775 & 3.0 & 100.0 & .661 \\
\hline
\end{tabular}

Table 4. Eigen Values of the Discriminant Functions

The first 2 canonical discriminant functions were used in the analysis. The first discriminant function acts highly efficient in separating the three groups because it accounts for the largest proportion of the discriminant variance. While the two functions significantly discriminate between the groups, the first function is more significant because it accounts for the largest proportion of the discriminant variance. The canonical correlation for a function is the square root of the ratio of between groups to total sums of squares. When squared, it is the proportion of total variability explained by differences between groups. It measures the association between the discriminant scores and the groups.

\subsection{Test for equality of Discriminant Functions}

To test whether the means of variables between the three groups are equal or not the Wilk's Lamda values are calculated. Wilk's Lambda is the proportion of the total variance in the discriminant scores not explained by differences among groups. Here $2.2 \%$ of the variance is not explained by group differences. Wilks' Lambda is used to test the null hypothesis that the means of all the variables across groups are equal and provides little information regarding the success of the model for classifying cases. The significance level of the observed Wilk's Lambda here is based on a Chi-square transformation of the statistic. The values of Wilks' Lambda and its associated Chi-square values, the degrees of freedom and the significance levels are given in Table 5. From the table it is clear that both Chi-square values indicate a statistically significant difference between the group centroids. Therefore, the null hypothesis that the means of all the 10 variables identified which are included in OS factor and EP factor are equal in the three groups is rejected. The alternate hypothesis that the means of all the 10 variables across the group are different is accepted. 


\begin{tabular}{|c|c|c|c|c|}
\hline Test of Function(s) & Wilks' Lambda & Chi-square & df & Sig. \\
\hline 1 through 2 & .022 & 318.787 & 20 & .000 \\
\hline 2 & .563 & 47.912 & 9 & .000 \\
\hline
\end{tabular}

Table 5. Wilks' Lambda of Discriminant Functions

\subsection{Contribution of variables to Discriminant Functions}

To ascertain the contributions of variables to discriminant functions, standardized coefficients and structure matrix are used. The details of standard coefficient and structure matrix are as follows:

Standardised Coefficient: The canonical discriminant function coefficients are the coefficients of a canonical variable. They are used to compute a canonical variable score for each case and the signs of the coefficients are arbitrary. The separation among the groups would be the same, if each coefficient is multiplied by $(-1)$. The standardized coefficients assess the contribution of each variable to the discriminant function. The coefficients of variables are presented in Table 6 . This has revealed the relative importance of the variables in discriminating the groups.

\begin{tabular}{|l|c|c|}
\hline \multirow{2}{*}{\multicolumn{1}{|c|}{ Variables }} & \multicolumn{2}{c|}{ Functions } \\
\cline { 2 - 3 } & 1 & 2 \\
\hline Safety Stock Planning & .697 & -.246 \\
\hline Capacity Utilization & .326 & -.661 \\
\hline Purchasing Effectiveness & .168 & .626 \\
\hline Demand Forecasting Frequency & .264 & -.063 \\
\hline IM Practice Pursued & .083 & .193 \\
\hline Management Attitude & .363 & .374 \\
\hline Employees Training & .299 & -.148 \\
\hline Interaction with Suppliers & .010 & .112 \\
\hline Interaction with Customers & -.010 & -.109 \\
\hline Supplier Empowerment & .141 & -.055 \\
\hline
\end{tabular}

Table 6. Standardized Canonical Discriminant Function Coefficients

\subsection{Structure Matrix}

It is based on the coefficients of the various variables that the structure matrix is formed, which is presented in Table 7. Structure matrix provides another way to study the usefulness of each variable in the discriminating function. When there are more than two groups and more 
than two variables, within group correlations are obtained for each canonical variable and variables with high statistically significant correlations for a particular canonical variable are grouped together and marked with an asterisk. As can be seen from Table 7, safety stock planning (SSP), management attitude (MA), employees training (ET), IM practice pursued (IMPP), demand forecasting frequency (DFF), and supplier empowerment (SE) respectively are the most important variables in the discriminating function 1 whereas purchasing effectiveness $(P E)$, capacity utilization (CU), interactions with suppliers (IS), and interactions with customers (IC) respectively are the most important discriminating variables in the discriminant function 2 .

\begin{tabular}{|l|c|c|}
\hline \multirow{2}{*}{\multicolumn{1}{c|}{ Variables }} & \multicolumn{2}{c|}{ Functions } \\
\cline { 2 - 3 } & 1 & 2 \\
\hline Safety Stock Planning & $.624^{*}$ & -.195 \\
\hline Management Attitude & $.460^{*}$ & .431 \\
\hline Employees Training & $.354^{*}$ & .093 \\
\hline IM practice Pursued & $.320^{*}$ & -.057 \\
\hline Demand Forecasting Frequency & $.311^{*}$ & -.017 \\
\hline Supplier Empowerment & $.236 *$ & .093 \\
\hline Purchasing Effectiveness & .317 & $.726^{*}$ \\
\hline Capacity Utilization & .297 & $-.536^{*}$ \\
\hline Interactions with Customers & -.109 & $-.227^{*}$ \\
\hline Interactions with Suppliers & -.081 & $-.091^{*}$ \\
\hline
\end{tabular}

Table 7. Structure Matrix

Pooled within-groups correlations between discriminating variables and standardized canonical discriminant functions Variables ordered by absolute size of correlation within function. * Largest absolute correlation between each variable and any discriminant function.

\begin{tabular}{|c|l|l|}
\hline SI. No & \multicolumn{1}{|c|}{ Group name } & \multicolumn{1}{|c|}{ Variables discriminate between groups } \\
\hline 1. & $\begin{array}{l}\text { Discriminating variables \& } \\
\text { function 1 }\end{array}$ & $\begin{array}{l}\text { Safety stock planning, Demand forecasting level, IM practice pursued, } \\
\text { Management attitude, Employees training, Supplier empowerment }\end{array}$ \\
\hline 2. & $\begin{array}{l}\text { Discriminating variables \& } \\
\text { function 2 }\end{array}$ & $\begin{array}{l}\text { Purchasing effectiveness, Capacity utilization, Interactions with suppliers and } \\
\text { Interactions with customers }\end{array}$ \\
\hline
\end{tabular}

Table 8. Discriminating variables between groups

\section{The first discriminant function acts highly efficient in separating the three groups} because it accounts for the largest proportion of the discriminant variance. Safety stock planning, Management attitude, Employees training, IM practice pursued, Demand forecasting level, and Supplier empowerment discriminate between groups with function 1 (group 1 and the rest) whereas Purchasing effectiveness, Capacity utilization, Interactions with suppliers and 
Interactions with customers clearly discriminate between the groups with function 2 (group 2 and group 3). The results are summarized in Table 8 . The results obtained are similar to those obtained from the factor analysis and the regression analysis conducted earlier.

The discriminant analysis has brought out the factors that contribute to IM performance. Therefore, to further substantiate the role of these factors in the ITR levels of machine tool SMEs, regression analysis is carried out. Subsequently regression analysis is done to examine the role of these variables in differentiating the levels of economic performance of these SMEs. The SMEs were ranked sequentially based on their cumulative score of 10 variables. Thereafter, SMEs with a cumulative score of 30 points and above were grouped as performing firms and SMEs with a cumulative score below 30 points were grouped as poorly performing firms. To check the adequacy of grouping the SMEs into two groups based on their cumulative score of the ten variables a discriminant analysis was conducted as done earlier. In this case there is only one discriminant function. The Eigen value of the discriminant function is shown in Table 9. The result brought out that the discriminant function is highly efficient in separating the two groups of SMEs.

\begin{tabular}{|c|c|c|c|c|}
\hline Function & Eigenvalue & $\%$ of Variance & Cumulative \% & Canonical Correlation \\
\hline 1 & 2.254 & 100.0 & 100.0 & 0.832 \\
\hline \multicolumn{4}{|c}{ Table 9. Eigenvalue of the Discriminant Function }
\end{tabular}

The First 1 canonical discriminant functions were used in the analysis. The Wilks' Lambda value of discriminant function is shown in Table 10. The statistically significant Wilks' Lambda brought out that the means of the cumulative scores across two groups are different and provides good information regarding the success of the model for classifying cases.

\begin{tabular}{|c|c|c|c|c|}
\hline Variable & Wilks' Lambda & Chi-square & df & Sig \\
\hline Cumulative Score & 0.307 & 104.417 & 1 & .000 \\
\hline
\end{tabular}

Table 10. Wilks' Lambda of Discriminant Function

The regression analysis was carried out with ITR as the dependent variable and the dummy variable for the cumulative score as the explanatory variable. The dummy variable assumed the value of 1 for better performing firm and 0 for poorly performing firm. Thus the regression equation is as follows:

$$
\text { ITR }=b_{0}+b_{1} \text { DUM Score }
$$


Here ITR represents inventory turnover and DUM Score represent dummy variable for the cumulative score for the variables influencing IM performance and $b_{1}$ is the beta coefficient of the explaining variable and $b_{0}$ is that of the intercept. The result is presented in Table 11 . The model is statistically significant as F-value is significant and the explanatory power of the model is reflected in the value of adjusted $R^{2}$ (about 29\%). The coefficient of the dummy variable is statistically significant implying that performing SMEs in terms of high cumulative score are better off in terms of their IM performance compared to poorly performing SMEs.

\begin{tabular}{|c|c|c|c|c|}
\hline Machine tool SMEs à & Beta Coefficients & 't' values & Significance level & VIF value \\
\hline Dummy Cumulative Score & 0.544 & 6.115 & 0.000 & 1.000 \\
\hline Constant & 2.269 & 4.553 & 0.000 & \\
\hline Adjusted R & \multicolumn{3}{|c|}{0.288} & \\
\hline F & & 37.319 & 0.000 & \\
\hline N & & 91 & &
\end{tabular}

Table 11. Regression Analysis of ITR with Dummy (Dependent Variable: ITR)

To ascertain whether the economic performance of the two groups is different a regression analysis was conducted with the dummy variable as explained earlier. The study has retained the same classification criteria for differentiating the groups. The regression analysis was carried out with gross value added (VA) as the dependent variable and the dummy variable for the cumulative score as the explanatory variable.

\section{Summary}

SMEs in inventory intensive manufacturing industries are likely to be aware of the need and importance of IM practices. Our study with reference to machine tools SMEs in Bangalore has indicated that these SMEs without exception are indeed aware of the importance of IM practices. However, when it comes to practice a majority of them pursue IM practice based on simple heuristics. Thus modern IM practices are only confined to a minority even in the inventory intensive machine tools manufacturing industry. In this paper an attempt is made to ascertain the key factors discriminating IM performance of SMEs by means of discriminant analysis. The study found that variables such as (a) safety stock planning, (b) employees training and (c) IM practice pursued discriminate the performing firms from the rest along with other variables such as (i) demand forecasting level, (ii) management attitude and (iii) supplier empowerment respectively whereas interactions with suppliers and interactions with customers along with purchasing effectiveness and capacity utilization discriminate between moderately performing group and poorly performing group. 
The study brought out that SMEs with a cumulative score of 30 and above are better off in terms of their IM performance and economic performance compared to those SMEs with a cumulative score of below 30 points. Overall, paying more attention to the identified variables will help SMEs to perform better on inventory management and economic performance fronts. Overall, the results clarified the fact that non technology factors also have an influence over IM performance. Through empirical data, it is established that 'technology' is not the only concern, but other factors related to human resource, economic, organizational and behavioural aspects of SMEs are also vital in improving their IM performance.

\section{References}

Ballou, H.R. (2000). Evaluating IM Performance Using Turnover Curve. International Journal of Physical Distribution \& Logistics Management, 30(1), 72-86.

http://dx.doi.org/10.1108/09600030010307993

Bhagwath, R., \& Sharma, M.K. (2007). Performance Measurement of Supply Chain Management a balanced score card approach. Computers and industrial Engineering, 53(1), 43-62. http://dx.doi.org/10.1016/j.cie.2007.04.001

Chandra, C., \& Grabis, J. (2005). Application of Multi-step Forecasting for Restraining the Bullwhip Effect and Improving Inventory Performance under Autoregressive Demand. European Journal of Operational Research, 166, 337-350.

http://dx.doi.org/10.1016/j.ejor.2004.02.012

Eloranta, E., \& Raisanen, J. (1988). Delivery Performance in Small-to-Medium-Scale Industry in Scandinavia. Production and Inventory Management Journal, 29(1), 50-55.

Flores, G.R., Wang, X.Z., \& Burgess, T.F. (2003). Tuning Inventory Policy Parameters in a Small Chemical Company. Journal of the Operational Research Society, 54, 350-361.

http://dx.doi.org/10.1057/palgrave.jors. 2601530

Gill, A., Biger, N., \& Mathur, N. (2010). The relationship between working capital management and profitability evidence from the United States. Business and Economic Journal, July 31, $1-9$.

Huin, S.F. (2004). Managing Deployment of ERP Systems Using Multi-agents. International Journal of Project Management, 22, 511-517. http://dx.doi.org/10.1016/j.ijproman.2003.12.005 
Jonsson, P., \& Mattsson, S.A.(2008). Inventory management practices and their implications on perceived planning performance. International Journal of Production Research, 46(7): 1787-1812. http://dx.doi.org/10.1080/00207540600988071

Koh, L.S.C., Deirbag, M., Bayraktar, E., Tatoglou, E., \& Zaim, S (2007). The impact of supply chain management practices on performance of SMEs. Industrial management \& data system, 107(1), 103-124. http://dx.doi.org/10.1108/02635570710719089

Koumanakos, D.P. (2008). The effect of IM on firm performance, International journal of productivity and performance management. 57(5), 335-369.

http://dx.doi.org/10.1108/17410400810881827

Maria, X.L., \& Jones, J.T. (2003). Quality Initiatives and Business Growth in Australian Manufacturing SMEs: An Exploratory Investigation. School of Commerce Research Paper Series, 03-3.

Mohanty, R.P. (1985). Inventory Problems under Multiple Constraints: Some Studies. Engineering Costs and Production Economics, 9, 355-367. http://dx.doi.org/10.1016/0167$188 \times(85) 90045-X$

Ng, S.O.E., Partington, E.C., \& Sculli, D. (1993). A Computer System for Inventory Management of Lighting Products: A Case Study. Computers in Industry, 22, 71-79. http://dx.doi.org/10.1016/0166-3615(93)90082-C

Nanjundan, S. (1994). Recent Developments in Small Scale Industry in Selected Countries and Lessons for India. National Council of Applied Economic Research and Friedrich-NaumannStiftung, New Delhi.

Natarajan, R. (1991). Inventory Management - The Big Picture. Production and Inventory Management Journal, 32(4), 29-31.

Palmer, A., \& Dean, H. (2000). How SMS Freed 40\% Capacity and Slashed Throughput Times. Manufacturing Computer Solutions, 6(11), 127-134.

Peenya Industrial Association (PIA) (2003). PIA Technical Directory. Peenya, Bangalore.

Rabinovich, E., Martin, E.D., \& Philip, T.E. (2003). Accessing the Effects of Operational Processes and Information Systems on Inventory Performance. Journal of Operations Management, 21(1), 63-80. http://dx.doi.org/10.1016/S0272-6963(02)00041-4

Saxena, V.D. (2012). Internationalization of SMEs n India: Opportunities and challenges. South Asian Journal of Marketing and Management Research, 12(9), 219-228. 
Sekaran, U. (2003). Research Methods for Business: A Skill Building Approach. Fourth Edition. Singapore: John Wiley \& Sons.

Sprague, L.G., \& Wacker, J.G. (1996). Macroeconomic Analyses of Inventories: Learning from Practice. International Journal of Production Economics, 45, 231-237.

http://dx.doi.org/10.1016/0925-5273(96)00002-3

Teunter, R., Babai, M., \& Syntetos, A. (2012). ABC Classification: Service Levels and Inventory Costs. Production and Operations Management, 19(3).

Wallin, C., Rugtusanatham, M.J., \& Rabinovitch, E. (2006). What is the Right Approach for a Purchased Item?. International Journal of Operations and Production Management, 26(1), 50-68. http://dx.doi.org/10.1108/01443570610637012

Zeng, A.Z., \& Hayya, J.C. (1999). The Performance of Two Popular Service Measures on Management Effectiveness in Inventory Control. International Journal of Production Economics, 58(2), 147-159. http://dx.doi.org/10.1016/S0925-5273(98)00210-2

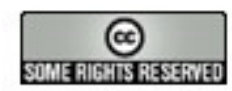

Article's contents are provided on a Attribution-Non Commercial 3.0 Creative commons license. Readers are allowed to copy, distribute and communicate article's contents, provided the author's and Journal of Industrial Engineering and Management's names are included. It must not be used for commercial purposes. To see the complete license contents, please visit http://creativecommons.org/licenses/by-nc/3.0/. 